\title{
Capacity Assignment Optimization of CHP Micro-grid with Heat Pumps
}

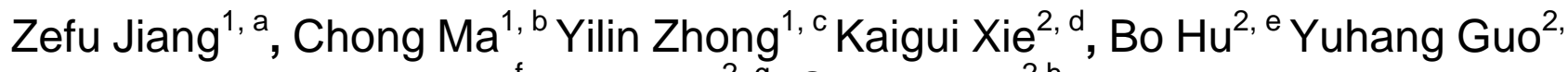 \\ , Yanlin $\mathrm{Li}^{2, g}$, Changlin $\mathrm{Li}^{2, \mathrm{~h}}$
}

${ }^{1}$ Power Grid Planning Research Center, Guizhou Power Grid Corporation, Guiyang 550002, China;

${ }^{2}$ State Key Laboratory of Power Transmission Equipment \& System Safety and New Technology, Chongqing University, Chongqing 400044, China.

ajiangzefu@126.com, b982474338@qq.com, ${ }^{\text {c3} 310319040 @ q q . c o m, ~}{ }^{d} k a i g u i x i e @ v i p .163 . c o m,{ }^{e} h b o y$ 8361@163.com, ${ }^{f}$ guoyh1990@163.com, ${ }^{9} 318797998 @ q q . c o m,{ }^{n}$ lichanglin2012@foxmail.com

Keywords: combined heat and power (CHP), micro-grid, optimal capacity assignment, genetic algorithm.

\begin{abstract}
Combined heat and power (CHP) micro-grid combines various distributed generation units, heat supply units, energy storage equipment, electric load, heat load and control devices together to provide users electricity and heat simultaneously. Heat and electricity could be transformed mutually under grid-connected mode and island mode, thus realizing high-efficiency utilization of new energies. However, such new energy unit has higher cost of investment per capacity compared to traditional generator unit. Unreasonable power capacity of micro-grid will cause not only wastes of wind energies and electric energies, but also over high cost of investment. Therefore, it is of important significance to plan capacities of units in CHP micro-grid reasonably according to local weather, wind speed and load. In this paper, a model for optimizing capacity assignment of CHP micro-grid with heat pumps was established. Targeting at normal operation of CHP micro-grid and optimum economical efficiency, this model combines historical meteorological data of regions to distribute capacities to wind turbines, CHP unit, lead-acid battery and the heat pump reasonably for warm and cold seasons respectively
\end{abstract}

\section{Introduction}

Currently, micro-grid has attracted wide attentions from both Chinese and foreign researchers. There are abundant research fruits of micro-grid and CHP technology. With the involvement of renewable energy sources, randomness and fluctuation of renewable energy sources brought many difficulties to the coordination control of micro-grid. Hence, reasonable assignment of micro-grid power capacity is the primary problem of micro-grid planning construction[1]. A series of fruits concerning optimal distribution of system capacity have been achieved by Chinese and foreign scholars.

In capacity assignment optimization model of CHP micro-grid, a mixed nonlinear integrated optimization mathematical model for cold-heat-electricity system was established in Reference [2]. Based on actual load of a building and targeting at the minimum total annual expenses, it explored the optimal capacity assignment under different cold-heat-electricity proportions and analyzed effect of cold-heat-electricity proportion on the optimal capacity assignment through sensitivity calculation. Reference [3] studied the relationship between the capacity assignment and the operation strategy of the cold-heat-electricity system. The established capacity assignment optimization model is a multi-objective planning model. The three objectives are minimum operation cost, minimum main equipments and maximum load rate of equipments. It got the optimum system operation strategy and the corresponding system configuration through case study. Reference [4] discussed heating efficiency and generating efficiency of micro-turbine under different load rates and established a more perfect capacity optimization model for CHP micro-grid.

Considering equipment type and external influencing factors, Reference [5] built an optimal planning model for distributed CHP system with photovoltaic array. This model paid attentions to 
optimization design of pipe network and was confirmed valid through the case study. Reference [6] studied the optimal capacity assignment of micro-grid with carbon emission adapter and heating load which aimed to achieve the minimum total operation cost. It concluded that micro-grid with CHP unit could reduce carbon emission significantly. Reference [7] considered various micro heat sources and made an operation strategy for micro-grid with photovoltaic cell, PEFCS battery, water electrolyser and heat pump. Based on this operation strategy, it optimized capacity assignment. Reference [8] built the CHP system model containing heat recovery boiler and thermal storage devices. Furthermore, it made static planning and dynamic planning, and analyzed effect of heating unit on heating performances of the system.

With the purpose of reducing conventional energy consumption and wind curtailment, this paper introduced heat pumps into the CHP micro-grid and made operation strategies for warm and cold seasons, respectively. A model used to optimize the capacity assignment of the CHP micro-grid was established. This model targets at the minimum equipment cost, operating maintenance cost, fuel consumption cost and wind curtailment penalty, and takes reliability of the system power and heat supply into consideration. The model was solved by using the self-adaptive genetic algorithm. A one-year case study was implemented. Results showed that the use of heat pumps could reduce capacity assignment to CHP unit and the lead-acid battery to a certain extent, but increase capacity assignment to the wind turbines. The CHP micro-grid with heat pumps could reduce fuel cost and wind curtailment significantly at basically same annual total cost. It could bring considerable economic benefits.

\section{CHP micro-grid system model}

A typical CHP micro-grid is shown in Fig.1. It consists various micro sources, such as micro CHP set (micro turbine), wind turbines, energy storage device, etc. The wind turbines takes wind energy as the motive power and serves as the renewable energy source set in the micro-grid. The micro CHP set uses natural gas as the primary energy source. After natural gas combustion, power made by high-temperature flue gas will drive the electric generator, while waste heat gas will enter into the lithium bromide chiller for heating. They undertake some electrical load and heating load of the micro-grid. The energy storage device is responsible for real-time charging and discharging according to operation of the micro-grid[9]. Additionally, the operation mode of the micro CHP set could be changed upon the demand of cooling, so that it could combine cooling and power and provide the system cold load.
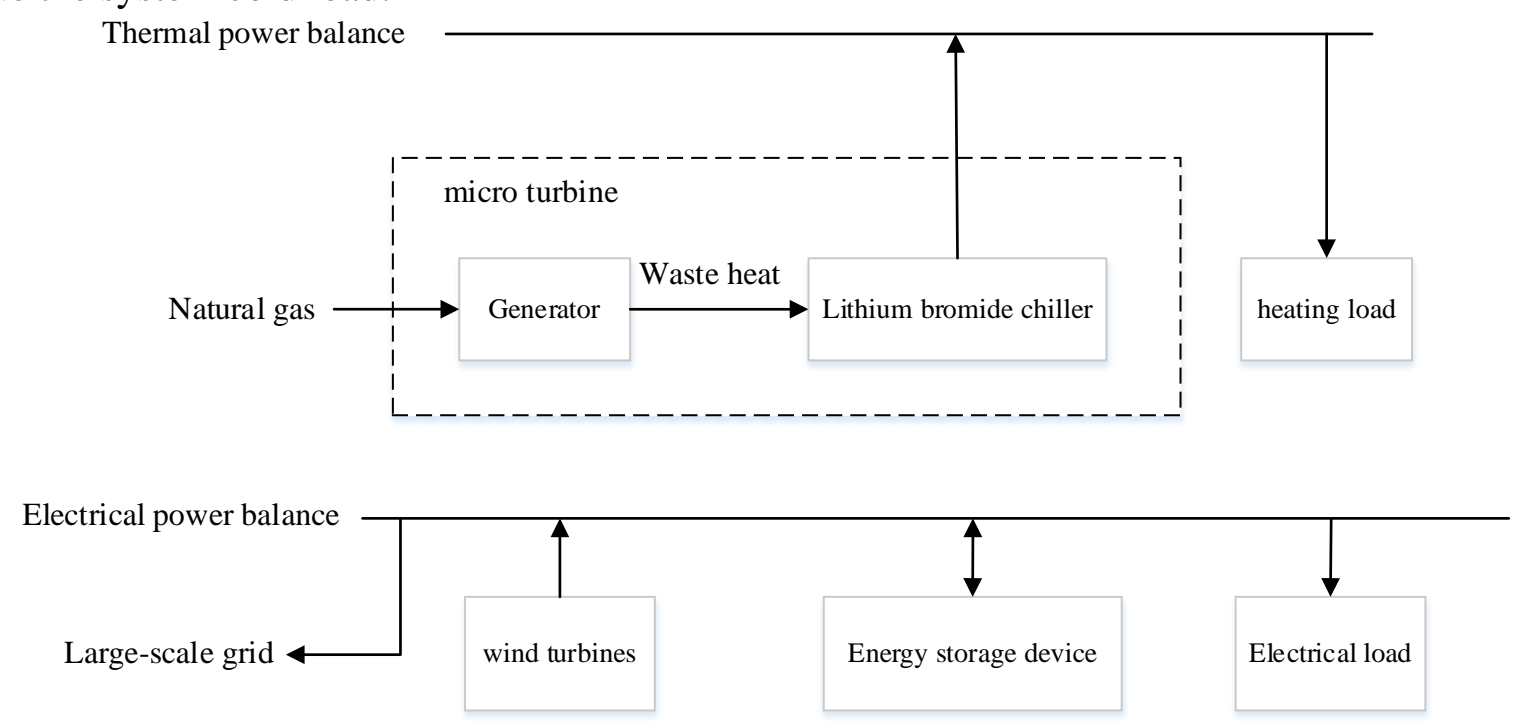

Fig.1 Typical CHP micro-grid 


\subsection{Micro-source output model}

\subsubsection{Output model of the wind turbines}

The output power $\left(P_{t}{ }^{w}\right)$ of the wind turbines in $1 \mathrm{~h}$ (one time frame) is determined by the average wind velocity $\left(v_{t}\right)$ at the height of the fan hub in this time frame. The segmented function is expressed as $^{[10]}$ :

$$
P_{t}^{w}= \begin{cases}0 & 0 \leq v_{t} \leq v_{c i} \\ \omega\left(v_{t}\right) & v_{c i}<v_{t} \leq v_{r} \\ P_{r}^{w} & v_{r}<v_{t}<v_{c o} \\ 0 & v_{t} \geq v_{c o}\end{cases}
$$

where $v_{c i}$ is cut-in wind speed, $v_{c o}$ is cut-out wind speed, $v_{r}$ is the rated wind speed, $P_{r}{ }^{w}$ is the rated output power of the wind turbines, $\omega\left(v_{t}\right)$ could be approximately viewed as a linear function. In other words,

$$
\omega\left(v_{t}\right)=P_{r}^{w} \frac{\left(v_{t}-v_{c i}\right)}{\left(v_{r}-v_{c i}\right)}
$$

\subsubsection{Output model of the CHP set}

Currently, internal combustion engine and micro turbine are the main CHP set. Micro turbine (MT) has unique advantages as the CHP set. Its generating efficiency reaches $40 \%$ and the comprehensive utilization of primary energy reaches as high as $90 \%{ }^{[12]}$. In this paper, MT was chosen as the CHP set.

The generating and heating outputs of MT when used as the CHP set are ${ }^{[13]}$ :

$$
\begin{aligned}
& P_{t}^{n}=G_{t}^{n} \eta_{e}^{n} q \\
& H_{t}^{n}=G_{t}^{n}\left(1-\eta_{e}^{n}-\eta_{1}^{n}\right) \delta_{h}^{n} q
\end{aligned}
$$

where $P_{t}{ }^{n}, H_{t}{ }^{n}, G_{t}{ }^{n}$ and $q$ are heating output, generating output, natural gas consumption and heating value of natural gas of the $n^{\text {th }}$ MT at $t ; \eta_{e}{ }^{n}$ and $\eta_{1}{ }^{n}$ are generating efficiency and heat loss coefficient of the $n^{\text {th }}$ MT at $t ; \delta_{h}{ }^{n}$ is the heating efficiency of the $n^{\text {th }}$ MT (the product of the heating efficiency of the lithium bromide chiller and the waste heat recovery efficiency). When load rate changes, $\eta_{1}{ }^{n}$ remains same, but the generating efficiency increases with the increase of load rate. The heat-to-power output ratio ${ }^{n}$ will change with the load rate. For small MT, the generating efficiency varies within a small range ${ }^{[14]}$, which could be approximately viewed same as $\eta_{e}{ }^{n}$ changes. Then, ${ }^{n}$ of the $n^{\text {th }}$ MT is a constant:

$$
\frac{H_{t}^{n}}{P_{t}^{n}}=\frac{\left(1-\eta_{e}^{n}-\eta_{1}^{n}\right) \delta_{h}^{n}}{\eta_{e}^{n}}=\theta^{n}
$$

\subsubsection{Lead-acid battery}

Battery is the most common and mature energy storage technique in micro-grid. This paper chose lead-acid battery as the energy storage device of the micro-grid. Main performance parameters of lead-acid battery include capacity $\left(C_{b a t}\right)$, maximum charge and discharge powers $\left(P_{c \max }^{b}\right.$ and $P_{d \max }^{b}$ ) and state of charge (SOC). SOC is the ratio between the current residual capacity of the battery and capacity under complete charge. It ranges from $0 \sim 1$, usually expressed in percentage (\%). SOC of battery must be controlled during the operation.

During charging, the variation law of SOC of the lead-acid battery $(S(t))$ is:

$$
S(t+1)=S(t)-\frac{P_{t}^{b} \eta_{c} \Delta t}{C_{b a t}}
$$

During discharging, $S(t)$ is:

$$
S(t+1)=S(t)-\frac{P_{t}^{b} \Delta t}{\eta_{d} C_{b a t}}
$$

where $S(t+1)$ and $S(t)$ are SOC of the lead-acid battery at $t+1$ and $t ; P_{t}^{b}$ is the charge-discharge power of the lead-acid battery at $t$ (discharge is positive and charge is negative); $\eta_{c}$ and $\eta_{d}$ are 
charge-discharge efficiency of the lead-acid battery; $\Delta t$ is time interval between two time frames; $C_{b a t}$ is capacity of the lead-acid battery.

The attrition rate of lead-acid battery is related with its depth of charge-discharge circulation. The relationship between the maximum number of charge-discharge cycles and depth of charge-discharge circulation could be expressed as ${ }^{[15],[16]}$ :

$$
N_{k}=\alpha_{1}+\alpha_{2} e^{\alpha_{3} D_{k}}+\alpha_{4} e^{\alpha_{5} D_{k}}
$$

where $N_{k}$ is the maximum number of charge-discharge cycles at $D_{k}$ discharge depth; $\alpha_{1}, \alpha_{2}, \alpha_{3}, \alpha_{4}$ and $\alpha_{5}$ are attrition related coefficients, which could be gained from the manufacturer.

\subsection{Chronological load model}

Traditional optimization of grid capacity assignment is generally based on a constant load. Due to the involvement of renewable energy sources, power output in the micro-grid is time-varying. Therefore, the optimization result will have certain error if still using the constant load model. To show the time-dependence of load, this paper took $1 \mathrm{~h}$ as a time frame and studied the chronological load curve, as shown in equation (9):

$$
P_{t}^{d}=P_{A} \cdot P_{\text {rate }}(t)
$$

where $P_{t}^{d}$ is electrical load demand at $t ; P_{A}$ is the peak load at the load point during the simulation period; $P_{\text {rate }}(t)$ is the load rate at $t$.

CHP micro-grid involves cooling and heating process. Cold and heating loads of building are determined by meteorological conditions and service conditions. The actual process is relatively complicated. For the convenient calculation, this paper mainly focused on air temperature. According to Energy Conservation Design Standard for Residential Buildings in Regions with Hot Summer and Cold Winter ${ }^{[17]}$, the winter indoor temperature was designed $18{ }^{\circ}$ and the summer air-conditioned indoor temperature was designed 26 .C

In this paper, cold and heating loads of CHP micro-grid apply load of common buildings. One time frame was set $1 \mathrm{~h}$ here. When the air temperature is very low and warming is necessary, heating load in $t\left(H_{t}^{d}\right)$ is calculated from ${ }^{[18]}$ :

$$
H_{t}^{d}=\left\{\begin{array}{cl}
(1+\mu) X_{h} V\left(T_{t}^{i}-T_{t}^{o}\right) & T_{t}^{i}>T_{t}^{o} \\
0 & T_{t}^{i} \leq T_{t}^{o}
\end{array}\right.
$$

where $\mu, X_{h}$ and $V$ are air permeability coefficient, heating coefficient and peripheral volume of the building; $T_{t}{ }^{o}$ is air temperature; $T_{t}{ }^{i}$ is the designed constant indoor temperature of buildings. According to Energy Conservation Design Standard for Residential Buildings in Regions with Hot Summer and Cold Winter, $T_{t}{ }^{i}$ was controlled 18 . ${ }^{\circ}$. o increase human comfort, $T_{t}{ }^{i}$ was increased to 24 Auring activity time (7:00-21:00).

Set $1 \mathrm{~h}$ as one time frame. When the air temperature is very high and cooling is needed, cold load in $t\left(C_{t}^{d}\right)$ was calculated from:

$$
C_{t}^{d}=\left\{\begin{array}{cl}
(1+\mu) X_{c} V\left(T_{t}^{o}-T_{t}^{i}\right) & T_{t}^{o}>T_{t}^{i} \\
0 & T_{t}^{o} \leq T_{t}^{i}
\end{array}\right.
$$

Where $X_{c}$ is cooling coefficient of the building.

\section{Operation strategy CHP micro-grid with heat pumps}

\subsection{Effect of heat pumps on CHP micro-grid}

The main cause of wind curtailment is the small adjustable extent of ${ }^{n}$ of the CHP set $\left({ }^{n}\right.$ is set a constant in this paper). Cue to electrical and heating load balance constraints, flexible adjustment of the system is limited. Hence, heat pumps were used in the CHP micro-grid.

Heat pump (HP) technology is a new energy technology which has attracted wide attentions from industries in recent years. As a distributed heating plant, HP could make heats flow from low-temperature medium to high-temperature one, acquire low-grade heat energy from the nature (air, water or soil), and output high-grade heat energy through electrical power. HP could be installed on 
user end of CHP micro-grid directly. Cooperating with CHP set in the micro-grid, it could meet users' heating demand in winter and cooling demand in winter.

Viewed from the micro-grid, physical parameters related with the HP are power consumption in $t$ $\left(P_{t}^{h p}\right)$ and exchanged heats through power in $t\left(H_{t}^{h p}\right) . H_{t}^{h p} / P_{t}^{h p}$ is coefficient of performance (COP):

$H_{t}^{h p}=P_{t}^{h p} \mathrm{COP}$

COP could be used to evaluate performance of the HP. It is defined as the ratio between heats transferred from low-temperature objects to high-temperature objects and the input electrical energy of the HP. COP is related with many factors like HP structure and air temperature. Under constant working conditions, COP is basically same.

Electrical and heat constraints of the CHP micro-grid system will change after HP is introduced in. The CHP micro-grid with HP is shown in Fig.2.

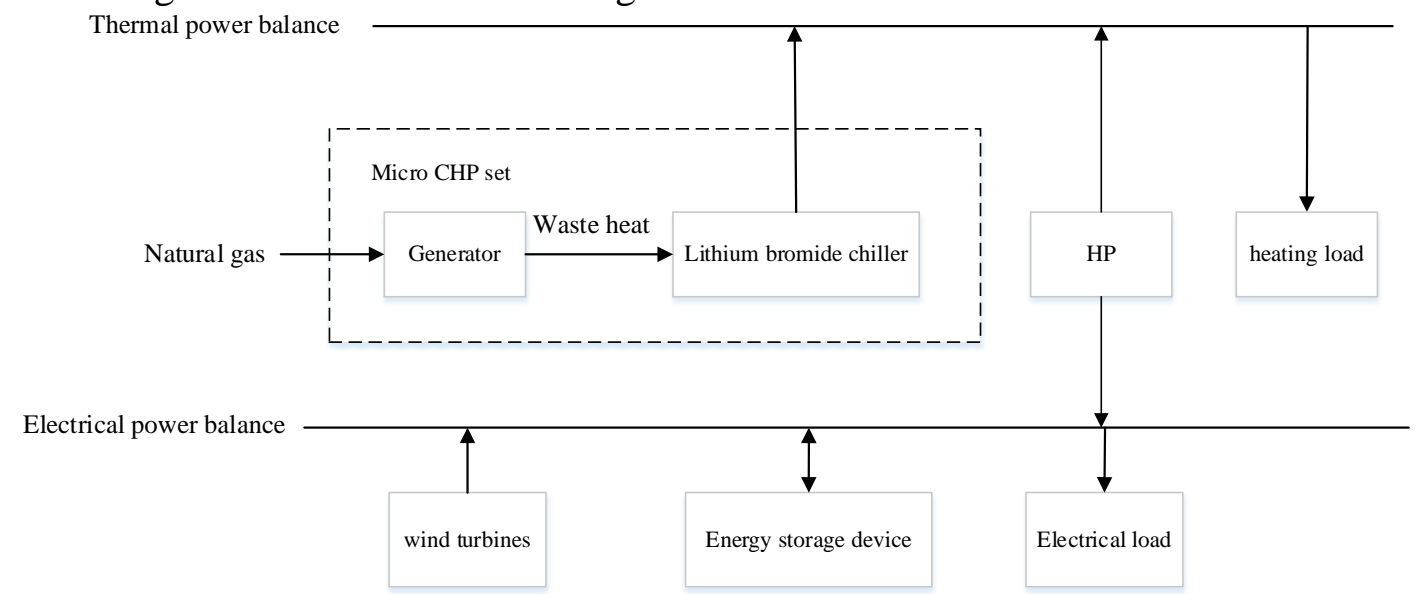

Fig.2 CHP micro-grid with HP

The energy balances of CHP micro-grid with HP include balance between electrical output of CHP set, wind turbines and energy storage device and electrical load as well as input power of HP; balance between heating (cooling) output of CHP set and HP and thermal (cold) load. When consuming electrical energies, the HP provides heat at a higher efficiency and could save consumption of primary energies.

Compared to the typical CHP micro-grid in Fig.1, the CHP micro-grid with HP could reduce heating (cooling) output of the CHP set through the HP compensation. This will increase electric energy consumption and enhances the renewable energy sources absorption of the micro-grid. In general, introducing HP could change proportions of electrical load and heating load, thus increasing wind and electricity absorption of the micro-grid, reducing repeated charge and discharge of the energy storage device, and saving fuel consumption of the set.

\subsection{Making operation strategy for CHP micro-grid with HP}

The CHP micro-grid with HP has stronger flexible adjustment than the typical CHP micro-grid. The following influences shall be considered when making operation strategy for CHP micro-grid with HP:

(1) Change the dispatching model of "fixing power based on heat"

The adjustable range of the heat-to-power output ratio ${ }^{n}$ of the CHP set is very small (approximately a constant in this paper). Without heat pump in the CHP micro-grid, output power of the CHP set must be determined according to cold and heating loads if it has to meet cold and heating loads of the system firstly. However, the CHP micro-grid with HP could cooling and heating by the HP. The HP will cooperate with the CHP set to meet cold and heating loads of the system, thus enhancing the dispatching flexibility of the CHP set.

(2) Priori deployment of cooling and heating devices

After the HP is introduced in, there will be diversified equipments that could meet heating load balance of the micro-grid. When making operation strategy, attentions shall be paid to priori deployment of both electrical energy and heating energy. Due to the higher working efficiency, less consumption of primary energy and higher heating economical efficiency of the HP than CHP set, HP 
deserves priori deployment to maintain operation at full load as much as possible.

In considering of these two points and the target of reducing conventional energy consumption and wind curtailment, the operation strategy making rules in this paper are:

Rule 1: The HP is the first choice of cooling and heating, while the CHP set is a backup.

Rule 2: The wind turbines shall be the priori choice of power supply. Ll wind power shall be consumed as much as possible.

Rule 3: The CHP set is used as the main power source of the micro-grid and is responsible for adjustment of the micro-grid.

Based on these rules, this paper made operation strategies of CHP micro-grid with HP for warm and cold seasons, respectively.

\subsection{Seasonal operation strategies of CHP micro-grid with HP}

The following text introduces the operation strategy for cold season.

(1) Firstly, it meets the heating load balance of the CHP micro-grid. Judge whether the heating load balance could be achieved by the HP alone. If yes, use the HP alone for heating; otherwise, open the CHP set. If it still fails to achieve satisfying heating load under the maximum output of the CHP set and the HP, the system has inadequate heating capacity.

(2) Secondly, it pays attention to electrical load balance of the CHP micro-grid.

a. If the power output of the CHP set and the wind turbines is larger than the sum of electrical load of users and input power of the HP, the lead-acid battery will charge. If the lead-acid battery is saturated, wind curtailment of the micro-grid occurs.

b. If the power output of the CHP set and the wind turbines is smaller than the sum of electrical load of users and input power of the HP, it shall resort to discharge of the lead-acid battery firstly. If the micro-source output sum is still smaller than electrical load of users, the power output of the CHP set shall be increased.

c. If the CHP set and the lead-acid battery still couldn't meet electrical load of users under the maximum output, the system has inadequate power supply capacity and electrical load shall be reduced.

The operation strategy of the CHP micro-grid with HP for cold season is shown in Fig.3. 


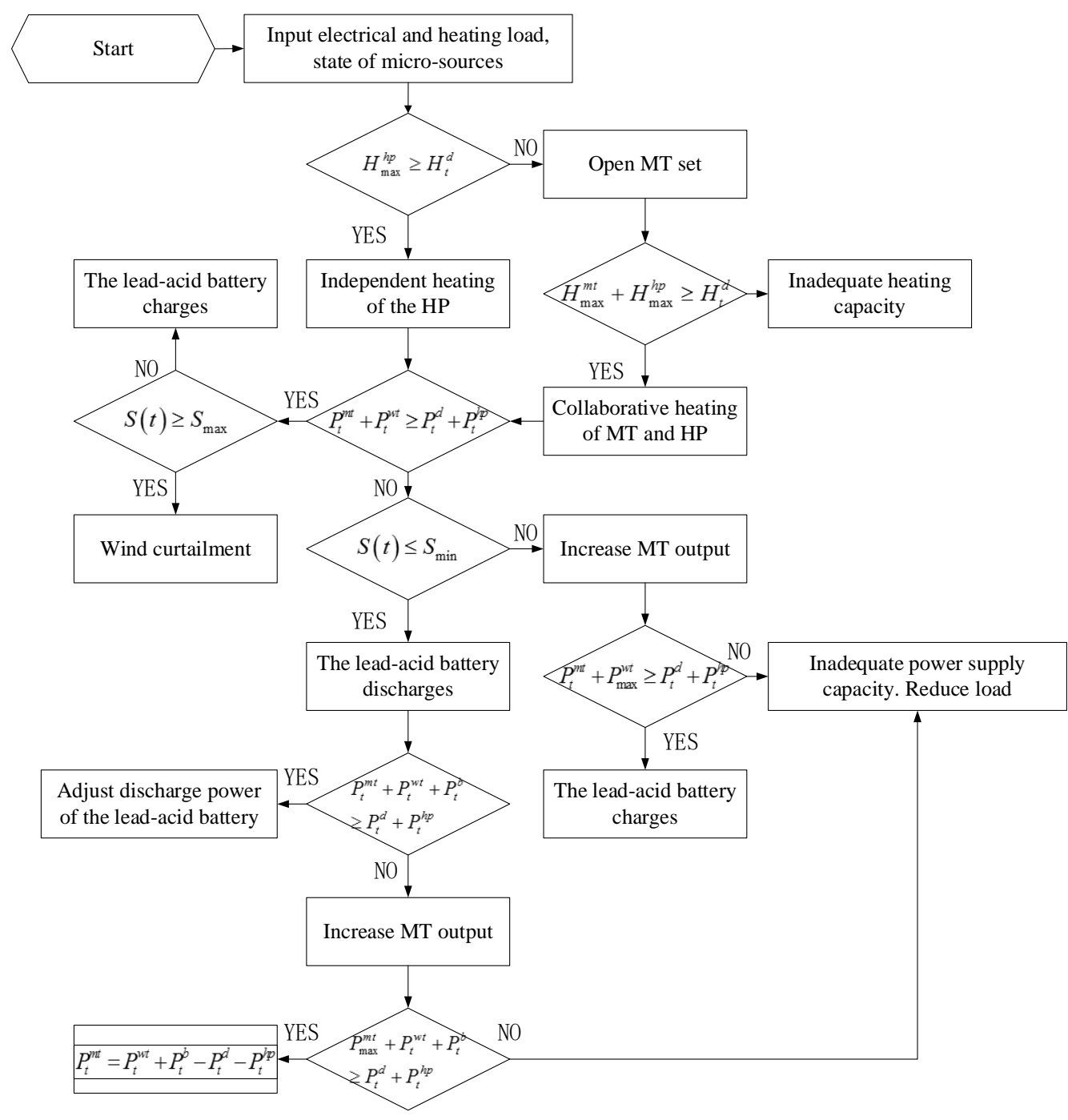

Fig.3 Operation strategy of CHP micro-grid with HP for cold season

The operation strategy for warm season is similar with that for cold season except for replacing heating load in Fig.3 with cold load as well as combined cooling and power of the CHP set. Deployment order of units in the micro-grid during HP cooling is same.

\section{Capacity assignment optimization model of CHP micro-grid with HP}

\subsection{Objective function}

The objective function of the energy storage capacity optimization model of the CHP micro-grid with HP is the minimum annual total cost of investment and operation, including investment cost of the wind turbines, MT, HP and energy storage system, fuel cost of MT, maintenance cost of sets, as well as wind curtailment penalty of the system:

$$
\min F=F_{i n}+F_{f}+F_{m}+F_{w c}
$$

where $F_{\text {in }}$ is the total investment cost of the system, $F_{f}$ is the fuel cost of MT, $F_{m}$ is maintenance cost of sets, and $F_{w c}$ is wind curtailment penalty of the system. They could be calculated from equations (14)-(22).

(1) Total investment cost of the system

The equivalent annual investment cost of equipments could be calculated from:

$$
\begin{aligned}
& F_{i n}=F_{i n}^{w t}+F_{i n}^{m t}+F_{i n}^{e h p}+F_{i n}^{b} \\
& F_{i n}^{w t}=N^{w t} c^{w t} \frac{r(1+r)^{y^{w t}}}{(1+r)^{y^{w t}}-1}
\end{aligned}
$$




$$
\begin{aligned}
& F_{i n}^{m t}=N^{m t} c^{m t} \frac{r(1+r)^{y^{m t}}}{(1+r)^{y^{m t}}-1} \\
& F_{i n}^{h p}=N^{h p} c^{h p} \frac{r(1+r)^{y^{h p}}}{(1+r)^{y^{y_{p}}}-1} \\
& F_{i n}^{b}=N^{b} c^{b} \frac{r(1+r)^{y^{b}}}{(1+r)^{y^{b}}-1}
\end{aligned}
$$

where $r$ is rate of discount; $F_{i n}^{w t}, F_{i n}^{m t}, F_{i n}^{h p}$ and $F_{i n}^{b}$ are initial investment costs of the wind turbines, MT, HP and lead-acid battery; $N^{w t}, N^{m t}, N^{h p}$ and $N^{b}$ are number of the wind turbines, MT, HP and lead-acid battery, which are planning variables of the model; $c^{w t}, c^{m t}, c^{h p}$ and $c^{b}$ are investment cost per unit of the wind turbines, MT, HP and lead-acid battery; $y^{w t}, y^{m t}, y^{h p}$ and $y^{b}$ are service life (year) of the wind turbines, MT, HP and lead-acid battery. The service life of the lead-acid battery is related with its operation process. If the lead-acid battery makes $N_{y}$ discharges under different discharge depths in one year, $y^{b}$ could be calculated from equation (19):

$$
y^{b}=\frac{1}{\sum_{k=0}^{N_{y}} \frac{1}{N_{k}}}
$$

where $N_{k}$ is the maximum discharge times at $D_{k}$ discharge depth (equation (8)).

(2) Fuel cost of MT

The fuel cost of MT is the cost of natural gas consumption in one year:

$$
F_{f}=P_{f} \sum_{t=1}^{8760} \frac{P_{t}^{m t}}{n_{e}^{m t} q} \Delta t
$$

where $P_{f}$ is unit natural gas price, $P_{t}^{m t}$ is power output of MT in $t, n_{e}^{m t}$ is generating efficiency of MT, $q$ is heating value of natural gas, and $\Delta t$ is length of time frame (1h here).

(3) Maintenance cost of set

The maintenance cost during the set operation is related with its installed capacity. Different types of set require different maintenance cost per capacity. The total annual maintenance cost of all sets in the micro-grid could be calculated from:

$$
F_{m}=\sum_{i=1}^{N} E_{i} K_{i}^{m}
$$

where $N$ is types of power source, $N=4$ in this paper; $E_{i}$ is the installed capacity of the $i^{\text {th }}$ power source; $K_{i}^{m}$ is the annual operation cost/maintenance cost (unit: $\$ / \mathrm{kW}$ ) of the $i^{\text {th }}$ micro source.

(4) Wind curtailment penalty

The wind curtailment penalty in the CHP micro-grid could be calculated from total wind curtailment of the year and penalty for unit wind curtailment:

$$
F_{w c}=\rho \sum_{t=1}^{8760}\left(P_{t}^{w}-P_{t}^{w a}\right) \Delta t
$$

where $\rho$ is the unit wind curtailment penalty coefficient; $P_{t}^{w}$ is output of the wind turbines, which could be calculated by the output model of wind turbines through time-series wind speed; $P_{t}^{\text {wa }}$ is the actually absorbed wind power of the micro-grid.

\subsection{Constraints}

(1) Quantity constraint of micro-sources

$$
\left\{\begin{array}{c}
0 \leq N^{w t} \leq N_{\max }^{w t} \\
0 \leq N^{m t} \leq N_{\max }^{m t} \\
0 \leq N^{h p} \leq N_{\max }^{h p} \\
N_{\min }^{b} \leq N^{b} \leq N_{\max }^{b}
\end{array}\right.
$$


where $N^{w t}, N^{m}, N^{h p}$ and $N^{b}$ are number of the wind turbines, MT, HP and lead-acid battery; $N_{\max }^{w t}, N_{\max }^{m t}$, $N_{\max }^{h p}$ and $N_{\max }^{b}$ are the maximum number of the wind turbines, MT, HP and lead-acid battery; $N_{\min }^{b}$ is the minimum number of the lead-acid battery.

(2) Output constraint of MT

Operating output of one MT is restricted by its maximum and minimum output:

$P_{\min }^{m t} \leq P_{t}^{m t} \leq P_{\max }^{m t}$

where $P_{t}^{m t}$ is the output of MT; $P_{\min }^{m t}$ and $P_{\max }^{m t}$ are the minimum and maximum power outputs of MT, which are limited by the heat-to-power output ratio $\theta^{m t}$. The heating output of MT is also limited. $H_{\text {min }}^{m t}$ and $H_{\text {max }}^{m t}$ are the minimum and maximum heating outputs of one MT.

(3) Power constraint of HP

Power constraint of HP in operation is:

$P_{\min }^{h p} \leq P_{t}^{h p} \leq P_{\max }^{h p}$

where $P_{\min }^{h p}$ and $P_{\max }^{h p}$ are the minimum and maximum input power of the HP in operation. $P_{\max }^{h p}$ is related with the HP capacity and is viewed approximately $P_{\max }^{h p}=E^{h p}$ in this paper. Meanwhile, the heating power of the HP is limited by COP. $H_{\min }^{h p}$ and $H_{\max }^{h p}$ are the minimum and maximum heating output of the HP in operation.

(4) Charge and discharge constraints of the lead-acid battery

The charge and discharge constraints of the lead-acid battery in operation are:

$P_{c \text { max }}^{b} \leq P_{t}^{b} \leq P_{d \max }^{b}$

where $P_{t}^{b}$ is the output of one lead-acid battery in $t$ (charge is positive and discharge is negative); $P_{c \max }^{b}$ and $P_{d \max }^{b}$ are the maximum charge and discharge powers of the lead-acid battery.

The SOC constraint of the lead-acid battery is:

$S_{\min } \leq S(t) \leq S_{\max }$

where $S_{\max }$ and $S_{\min }$ are the upper and lower limits of SOC of the lead-acid battery.

(5) Power supply and heating reliability constraints of the micro-grid

$L O L P \leq L O L P_{\max }$

$L O H P \leq L O H P_{\max }$

where $L O L P$ is the loss of load probability and $L O L P_{\max }$ is the allowable maximum $L O L P$ of the system; $L O H P$ is loss of heat probability and $L O H P_{\max }$ is the allowable maximum $L O H P$ of the system.

In this paper, $L O L P$ and $L O H P$ were calculated with the sequential Monte-Carlo simulation method in the Reference [19]. In the CHP micro-grid, operating state of the system could be acquired through random sampling of the normal operation time and post-malfunction repair time of MT and the wind turbines. During operation, electrical load will be reduced upon inadequate power output, that is, all power output couldn't meet electrical load demands. If electrical load reduction occurs in $t$, the electricity-cut ( $\left.E_{t}^{\text {cut }}\right)$ is:

$$
E_{t}^{\text {cut }}=\left(P_{t}^{\text {load }}+N^{h p} P_{t}^{h p}-N^{b} P_{t}^{b}-N_{a}^{w t} P_{t}^{w}-N_{a}^{m t} P_{t}^{m t}\right) \cdot \Delta t
$$

where $N_{a}^{w t}$ and $N_{a}^{m t}$ are the number of normal-operation wind turbines and MT in $t$. If $T_{e}^{\text {cut }}$ represents time frames of electricity-cut in one sampling year, the LOLP of the micro-grid in this sampling year is:

$$
L O L P_{k}=\sum_{t=1}^{T_{e}^{\text {cut }}} E_{t}^{\text {cut }} / \sum_{t=1}^{8760}\left(P_{t}^{\text {load }} \cdot \Delta t\right)
$$

During operation, heating load will be reduced upon inadequate heating output of the system, that is, the heating output of the MT and HP couldn't meet the heating load demands. If heating load reduction occurs in $t$, the heating-cut $\left(Q_{t}^{\text {cut }}\right)$ is:

$$
Q_{t}^{\text {cut }}=\left(H_{t}^{\text {load }}-N^{h p} H_{t}^{h p}-N_{a}^{m t} H_{t}^{m t}\right) \cdot \Delta t
$$


If $T_{q}^{\text {cut }}$ represents time frames of heating-cut in one sampling year, the LOHP of the micro-grid in this sampling year is:

$$
L O H P_{k}=\sum_{t=1}^{T_{q}^{\text {cut }}} Q_{t}^{\text {cut }} / \sum_{t=1}^{8760}\left(H_{t}^{\text {load }} \cdot \Delta t\right)
$$

Based on calculation of annual reliability index in the simulation period ( $Y$ years), the annual $L O L P$ and $L O H P$ of the system could be gained:

$$
\begin{aligned}
& L O L P=\frac{1}{Y} \sum_{k=1}^{Y} L O L P_{k} \\
& L O H P=\frac{1}{Y} \sum_{k=1}^{Y} L O H P_{k}
\end{aligned}
$$

\section{Solving the capacity assignment optimization model}

In the capacity assignment optimization model of CHP micro-grid with HP, variables that have to be solved include number of wind turbines $\left(N^{w t}\right)$, number of MT $\left(N^{m t}\right)$, number of HP $\left(N^{h p}\right)$ and number of lead-acid battery $\left(N^{b}\right)$. All of them are integral variables. Chromosome coding was implemented to these variables through binary form.

Among constraint conditions of the capacity assignment optimization model of the CHP micro-grid with HP, the reliability constraint is difficult to be expressed by analytic expression of optimization variables. Therefore, reliability constraint was limited by penalty function method in this paper. According to the objective function, the fitness function when solving with genetic algorithm could be expressed as:

$$
\begin{aligned}
& \text { fitness }(A)=\exp (-(F(A)+L(A)+K(A))) \\
& L(A)=\left\{\begin{array}{cc}
C_{1} \cdot\left(L O L P-L O L P_{\max }\right) & L O L P>L O L P_{\max } \\
0 & L O L P \leq L O L P_{\max }
\end{array}\right. \\
& K(A)=\left\{\begin{array}{cc}
C_{2} \cdot\left(L O H P-L O H P_{\max }\right) & L O H P>L O H P_{\max } \\
0 & L O H P \leq L O H P_{\max }
\end{array}\right.
\end{aligned}
$$

where $F(A)$ is the objective function value of chromosome $A$. It can be calculated from equation (36) that $L(A)$ is reliability penalty function of chromosome $A$ and $K(A)$ is the penalty function of $L O H P$ of .chromosome $A$. They were calculated from equation (37) and (38) through the sequential Monte-Carlo simulation method. $C_{1}$ and $C_{2}$ are big positive constants.

The genetic algorithm process to solve the capacity assignment optimization model of the CHP micro-grid with HP is introduced as follows:

Step1: Input annual wind speed, electrical load, cold and heating load as well as micro-sources parameters. Set calculation parameters of genetic algorithm, such as population quantity and iterations.

Step2: Generate the initial population through random number method and make chromosome coding.

Step3: Decoding the chromosome and adjust quantities of micro-sources to meet the quantity constraint of micro-sources.

Step4: Calculate fuel cost and wind curtailment penalty according to operation strategies for cold and warm seasons, without consideration to malfunctions.

Step5: Considering failure rates of the wind turbines and CHP set, calculate LOLP and LOHP of the current individual through sequential Monte-Carlo simulation. Calculate individual fitness value through the fitness function.

Step6: Select through operators. Make crossover and mutation operations.

Step7: Judge whether meets condition of iteration end or reaches the maximum iterations. If yes, end the calculation and output result; otherwise, turn to Step3.

The flowchart of the genetic algorithm is shown in Fig.4. 


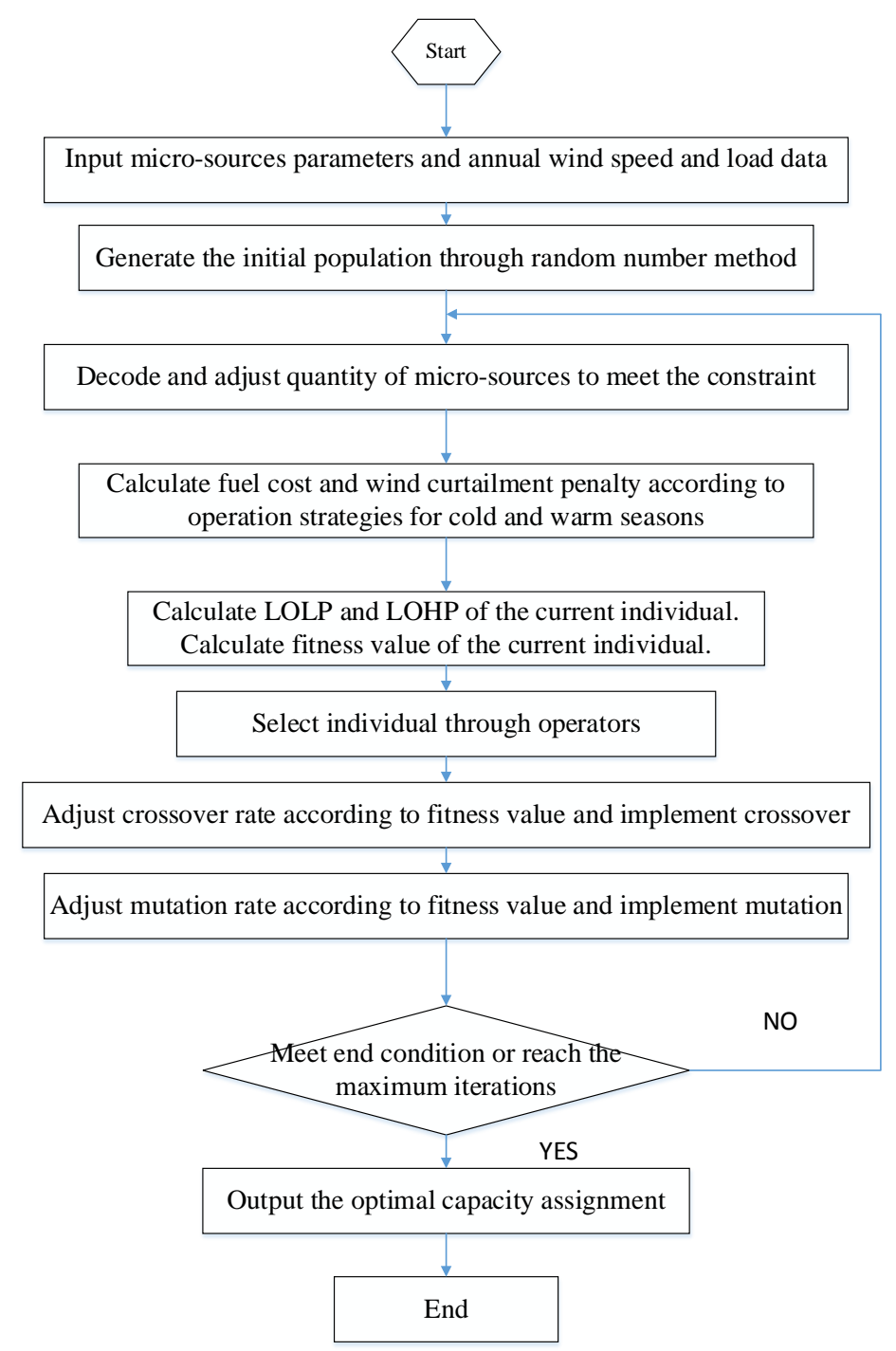

Fig.4 Algorithm flowchart of capacity assignment optimization of CHP micro-grid with HP

\section{Case study}

\subsection{Parameter setting for a planning isolated CHP micro-grid}

This paper optimized capacity assignment of an isolated CHP micro-grid in one region to verify the validity of the proposed model. This region has distinct cold and warm seasons: the cold season lasts from October to March of the next year and the warm season lasts from March to September. In cold season, heating load of the micro-grid is mainly warming load of buildings. The CHP set is in the state of combined power and heat, while the HP is responsible for heating. In warm season, the heating load of the micro-grid is mainly cooling load of buildings. The CHP set is in the state of combined power and cooling, while the HP is responsible for cooling.

The study period was set one year and $\Delta t$ was set $1 \mathrm{~h}$. The time sequence of wind speed of the whole year in the study area is shown in Fig.5. The peak load of the micro-grid is $500 \mathrm{~kW}$. Time sequence of per unit value (October $\sim$ September of the next year) is presented in Fig.6.

The temperature time sequence of the year (October $\sim$ September of the next year) is shown in Fig.7. MT and HP adopt different operating modes under different temperatures. According to local weather conditions, this region is divided into cold and warm seasons. The cold season starts from October to March of the next year. During this season, the micro-grid has heating load. The MT adopts the combined power and heat mode, while the HP adopts the heating mode. The warm season is from April to September. During this season, the micro-grid has cold load. The MT adopts the combined power and cold mode, whereas the HP adopts the cooling mode. 
With the cold and heating load prediction model, the time sequence of heating load in cold season and time sequence of cold load in warm season could be gained (Fig.8). The maximum heating load and cold load are $490 \mathrm{~kW}$ and $440 \mathrm{~kW}$, respectively.

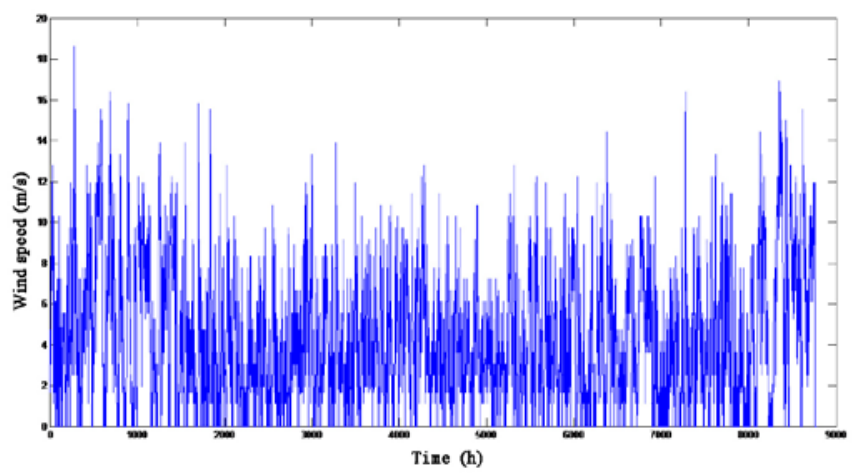

Fig.5 Time sequence of wind speed all year round

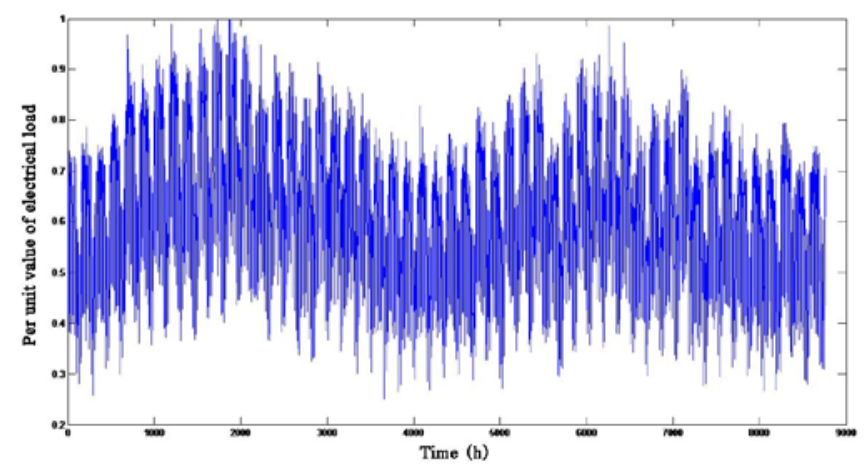

Fig.6 Time sequence of per unit value of electrical load all year round

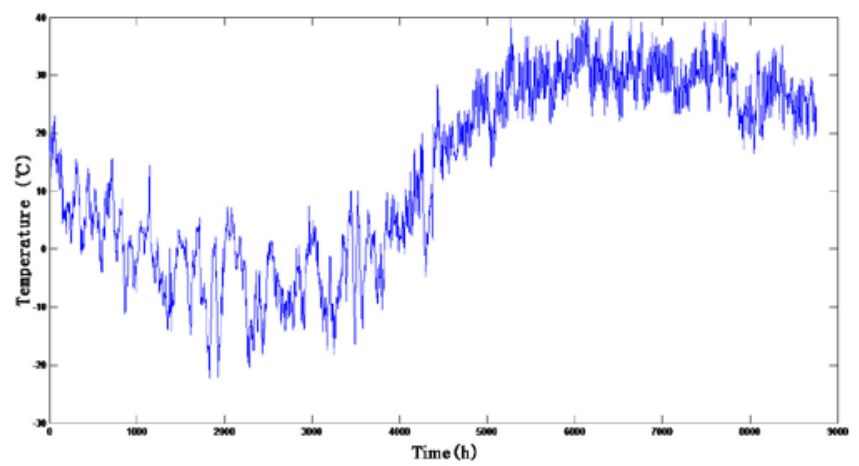

Fig.7 Time sequence of temperature all year round

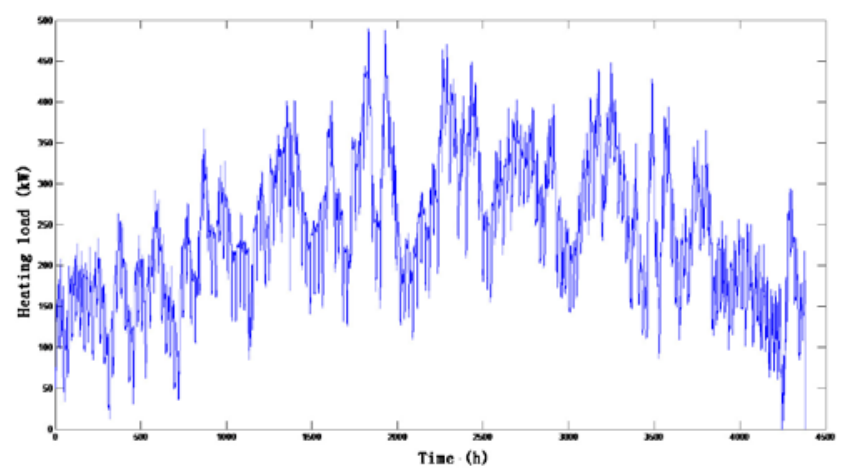

Fig.8(a) Time sequence of heating load in cold season 


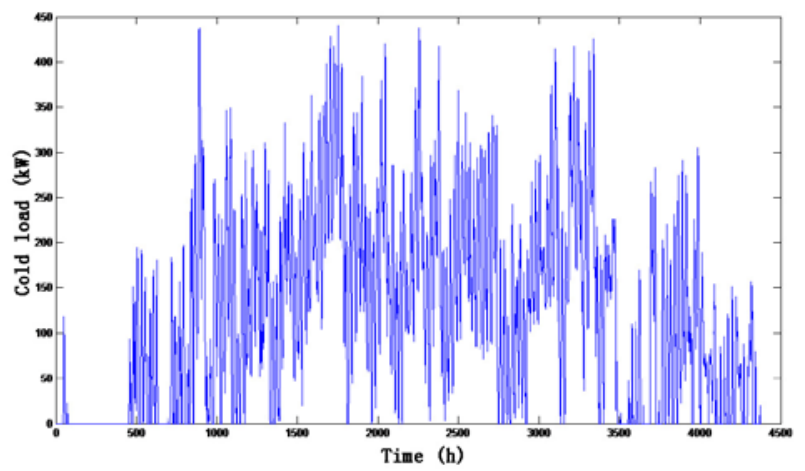

Fig.8(b) Time sequence of cold load in warm season

Parameters of micro-sources in the micro-grid are set as Table 1-Table 4 according to parameter setting in Reference [9], [14] and [15].

Table 1 Parameters of wind turbines

\begin{tabular}{cccccccc}
\hline $\begin{array}{c}\text { Type of } \\
\text { micro-sour } \\
\text { ces }\end{array}$ & $\begin{array}{c}\text { Cut-i } \\
\mathrm{n} \\
\text { wind } \\
\text { speed } \\
(\mathrm{m} / \mathrm{s})\end{array}$ & $\begin{array}{c}\text { Cut-o } \\
\text { ut } \\
\text { wind } \\
\text { speed } \\
(\mathrm{m} / \mathrm{s})\end{array}$ & $\begin{array}{c}\text { Rated } \\
\text { wind } \\
\text { speed } \\
(\mathrm{m} / \mathrm{s})\end{array}$ & $\begin{array}{c}\text { Rated } \\
\text { owwer } \\
(\mathrm{kW})\end{array}$ & $\begin{array}{c}\text { Investmen } \\
\text { t cost per } \\
\text { unit } \\
(\$ / \mathrm{unit})\end{array}$ & $\begin{array}{c}\text { Operation } \\
\text { maintenan } \\
\text { ce ratio } \\
(\$ / \mathrm{kW})\end{array}$ & $\begin{array}{c}\text { Servic } \\
\text { e life } \\
(\mathrm{Y})\end{array}$ \\
\hline WT & 5 & 22 & 15 & 30 & 45000 & 100 & 20 \\
\hline
\end{tabular}


Table 2 Parameters of CHP units

\begin{tabular}{|c|c|c|c|c|c|c|c|}
\hline \multirow{2}{*}{$\begin{array}{c}\text { Type of } \\
\text { micro-source } \\
\text { s }\end{array}$} & \multicolumn{2}{|c|}{$\begin{array}{l}\text { Generated power } \\
(\mathrm{kW})\end{array}$} & \multicolumn{2}{|c|}{$\begin{array}{c}\text { Heat } \\
\text { (cold)-to-power } \\
\text { output ratio }\end{array}$} & \multirow{2}{*}{$\begin{array}{c}\text { Investmen } \\
\text { t cost per } \\
\text { unit } \\
\text { (\$/unit) }\end{array}$} & \multirow{2}{*}{$\begin{array}{c}\text { Operation } \\
/ \\
\text { maintena } \\
\text { nce ratio } \\
(\$ / \mathrm{kW})\end{array}$} & \multirow{2}{*}{$\begin{array}{l}\text { Servi } \\
\text { ce life } \\
(\mathrm{Y})\end{array}$} \\
\hline & $\begin{array}{l}\text { Lower } \\
\text { limit }\end{array}$ & $\begin{array}{l}\text { Upper } \\
\text { limit }\end{array}$ & $\begin{array}{c}\text { Cold } \\
\text { seaso } \\
\text { n }\end{array}$ & $\begin{array}{l}\text { Warm } \\
\text { season }\end{array}$ & & & \\
\hline MT & 20 & 70 & 1.2 & 1.1 & 150000 & 120 & 20 \\
\hline
\end{tabular}

Table 3 Parameters of Heat Pump

\begin{tabular}{|c|c|c|c|c|c|c|c|}
\hline \multirow{2}{*}{$\begin{array}{c}\text { Type of } \\
\text { micro-source } \\
\text { s }\end{array}$} & \multicolumn{2}{|c|}{$\begin{array}{c}\text { Input power } \\
\text { Pthp(kW) }\end{array}$} & \multicolumn{2}{|c|}{$\mathrm{COP}$} & \multirow{2}{*}{$\begin{array}{l}\text { Investm } \\
\text { ent cost } \\
\text { per unit } \\
\text { Chp(\$/u } \\
\text { nit) } \\
\end{array}$} & \multirow{2}{*}{$\begin{array}{c}\text { Operation } \\
/ \\
\text { maintena } \\
\text { nce ratio } \\
(\$ / \mathrm{kW})\end{array}$} & \multirow{2}{*}{$\begin{array}{c}\text { Servi } \\
\text { ce } \\
\text { life } \\
(\mathrm{Y})\end{array}$} \\
\hline & Lower limit & $\begin{array}{l}\text { Upper } \\
\text { limit }\end{array}$ & $\begin{array}{l}\text { Cold } \\
\text { season }\end{array}$ & $\begin{array}{l}\text { Warm } \\
\text { season }\end{array}$ & & & \\
\hline HP & 3 & 10 & 3 & 2.5 & 30000 & 80 & 20 \\
\hline
\end{tabular}

Table 4 Parameters of lead-acid battery

\begin{tabular}{|c|c|c|c|c|c|c|c|}
\hline \multirow{2}{*}{$\begin{array}{c}\text { Type of } \\
\text { micro-source } \\
\text { s }\end{array}$} & \multicolumn{2}{|c|}{ Rated power $(\mathrm{kW})$} & \multirow{2}{*}{$\begin{array}{c}\text { Capacity } \\
\text { (kWh) }\end{array}$} & \multirow{2}{*}{$\begin{array}{l}\text { Charge } \\
\text {-discha } \\
\text { rge } \\
\text { efficien } \\
\text { cy } \eta\end{array}$} & \multicolumn{2}{|c|}{ SOC } & \multirow{2}{*}{$\begin{array}{c}\text { Investm } \\
\text { ent cost } \\
\text { per unit } \\
\text { cb(\$/uni } \\
\text { t) }\end{array}$} \\
\hline & $P_{c \max }^{b}$ & $P_{d \max }^{b}$ & & & Smin & Smax & \\
\hline B & -20 & 20 & 80 & 0.95 & 0.3 & 1.0 & 2000 \\
\hline
\end{tabular}

Service life of the lead-acid battery is related with its charge and discharge process. It could be calculated from equation (28). When $\rho=2 \$ / \mathrm{kW} \cdot \mathrm{h}$, the heating value and price of natural gas are $37 \mathrm{MJ} / \mathrm{m}^{3}$ and $0.4 \$ / \mathrm{m}^{3}$, respectively. $L O L P_{\max }=2 \times 10^{-3}$ and $L O H P_{\max }=3 \times 10^{-3}$; the mean time to failure (MTTF) and the mean time to repair (MTTR) of wind turbines are $2160 \mathrm{~h}$ and $48 \mathrm{~h}$, respectively. MTTF and MTTR of MT are 1080h and 24h, respectively. The simulation time of reliability calculation $(Y)$ is 100 years.

\subsection{Capacity assignment optimization of typical CHP micro-grid without HP}

Based on the capacity assignment optimization model of CHP micro-grid with HP, set the maximum number of HP 0 . Combining with wind speed, electrical load, heating load and cold load in Fig.5-Fig.8 as well as parameters of micro-sources in Table 1-Table 4, the total cost of investment and operation of the CHP micro-grid in one year is optimized. Results are listed in Table 5.

Table 5 Capacity assignment optimization results of CHP micro-grid without HP

\begin{tabular}{ccccccccc}
\hline \multicolumn{4}{c}{ Micro-source units (pc) } & \multicolumn{5}{c}{ Cost $(\$ /$ year) } \\
\hline $\begin{array}{c}\text { Wind } \\
\text { turbines }\end{array}$ & $\begin{array}{c}\text { CHP } \\
\text { set }\end{array}$ & HP & $\begin{array}{c}\text { Lead-ac } \\
\text { id } \\
\text { battery }\end{array}$ & $\begin{array}{c}\text { Investme } \\
\text { nt cost }\end{array}$ & Fuel cost & $\begin{array}{c}\text { Maintena } \\
\text { nce cost }\end{array}$ & $\begin{array}{c}\text { Wind } \\
\text { curtailment } \\
\text { penalty }\end{array}$ & Total \\
\hline 12 & 7 & - & 20 & 197922 & 229559 & 94800 & 168213 & $\begin{array}{c}69049 \\
4\end{array}$ \\
\hline
\end{tabular}

The annual cost of typical CHP micro-grid with optimal capacity assignment is 690,949 dollars. Among them, 1/3 are fuel cost and 1/4 are wind curtailment penalty.

\subsection{Capacity assignment optimization of CHP micro-grid without HP}

Based on the capacity assignment optimization model of CHP micro-grid with HP and optimization results of CHP micro-grid without HP, set the maximum number of HP 20. Combining with wind speed, electrical load, heating load and cold load in Fig.5-Fig.8 as well as parameters of micro-sources in Table 1-Table 4, the total cost of investment and operation of the CHP micro-grid with HP in one year is optimized. Results are shown in Table 6. 
Table 6 Capacity assignment optimization results of CHP micro-grid with HP

\begin{tabular}{ccccccccc}
\hline \multicolumn{4}{c}{ Micro-source units (pc) } & \multicolumn{5}{c}{ Cost (\$/year) } \\
\hline $\begin{array}{c}\text { Wind } \\
\text { turbine } \\
\text { s }\end{array}$ & $\begin{array}{c}\text { CHP } \\
\text { set }\end{array}$ & HP & $\begin{array}{c}\text { Lead-a } \\
\text { cid } \\
\text { battery }\end{array}$ & $\begin{array}{c}\text { Investment } \\
\text { cost }\end{array}$ & Fuel cost & $\begin{array}{c}\text { Maintenan } \\
\text { ce cost }\end{array}$ & $\begin{array}{c}\text { Wind } \\
\text { curtailment } \\
\text { penalty }\end{array}$ & Total \\
\hline 15 & 5 & 6 & 14 & 195175 & 186485 & 103000 & 89181 & $\begin{array}{c}57384 \\
1\end{array}$ \\
\hline
\end{tabular}

The annual cost of CHP micro-grid with HP under optimal capacity assignment is 573,841 dollars. Among them, $1 / 3$ are investment cost and fuel cost. Wind curtailment penalty accounts for a small proportion, only $18 \%$.

Fig.9 presents the comparison of optimal capacity assignment of Case 1 and Case 2.

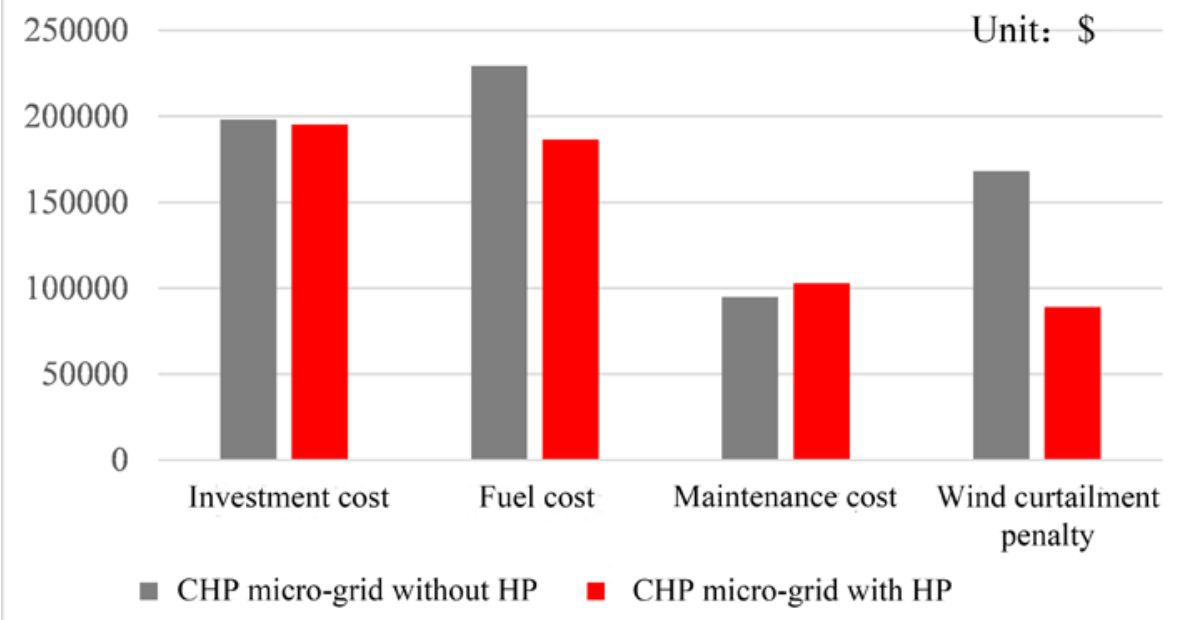

Fig.9 Comparison of the optimal capacity assignment between CHP micro-grid with and without $\mathrm{HP}$

Based on comparison between Case 1 and Case 2, we can conclude that:

(1) In micro-grid without heat pump, CHP set is responsible for both cold and heating loads, thus consuming a great amount of fuels. Meanwhile, CHP set has to output electricity in proportional to cold and heating loads of the micro-grid. This will cause wastes of wind and electricity under high wind speed and saturation of lead-acid battery, generating wind curtailment penalty.

(2) In micro-grid with heat pumps, cold and heating loads are provided by both CHP set and heat pumps. The heat pumps provide heats at the cost of electricity, which presents high heating efficiency and lower consumption of primary energy sources per unit heat energy output. The micro-grid has stronger consumption capacity of wind and electricity. This explains why there are two less CHP sets and two more wind turbines in Case 2 than Case 1. After heat pumps are used in the micro-grid, there's fewer occurrences of excessive wind and electricity. Therefore, there are 6 fewer lead-acid batteries in Case 2 than Case 1. The annual investment costs of Case 1 and Case 2 are basically same.

(3) Case 2 applies heat pumps for heating and cooling, which could save primary energy sources, and reduce fuel consumption by the CHP set. Therefore, the fuel cost in Case 2 is $18.7 \%$ lower than that of the Case 1.

(4) Case 2 which uses heat pumps consumes electricity for heating and cooling. It increases power supply adjustment of the CHP micro-grid, enhances wind and electricity absorption, but reduces wind curtailment penalty by $47 \%$ than that of Case 1 .

(5) Adding heat pumps when planning capacity for CHP micro-grid could lower total cost in the planning year. The total cost of Case 2 is $16.9 \%$ lower than that of Case 1 . 


\section{Conclusions}

This paper introduces research status of capacity assignment optimization of CHP micro-grid and points out existing shortcomings. Based on the operation strategies of CHP micro-grid with HP for cold and warm seasons, targeting at the minimum total cost (including equipment cost, operating maintenance cost, fuel cost and wind curtailment penalty), a capacity assignment optimization model of CHP micro-grid is established. It is solved by using genetic algorithm.

A one-year case study is implemented. Results show that the use of heat pumps could reduce capacity allocated for CHP set and lead-acid batteries, but increase capacity for wind turbines. The CHP micro-grid with heat pumps could reduce fuel cost and wind curtailment significantly at basically same annual total cost. It could bring considerable economic benefits.

\section{Acknowledgment}

This work is supported by the China Southern Power Grid Program (No. K-GZ2013-468).

\section{References}

[1]. Teleke S, Baran M E, Bhattacharya S, et al. Optimal control of battery energy storage for wind farm dispatching[J]. IEEE Transactions on Energy Conversion, 2010, 25(3): 787-794.

[2]. LI Zhao-zhen, SHI Yu-mei, HUANG Xing-hua. Influence of Load composition on the Optimized Configuration of a Combined Cooling,Heating and Power(CCHP) Cogeneration System [J]. Journal of Engineering for Thermal Energy and Power,2008,(6).

[3]. LI Yun, HUANG Xing-hua. Integrated Optimization of Scheme and Operation Strategy for CCHP System [J]. Journal of Power Engineering. 2007, 26(6): 894-898.

[4]. Bando S, Watanabe H, Asano H, Tsujita S. Impacts of various characteristics of electricity and heat demand on the optimal configuration of a microgrid[J]. IEEJ Transactions on Power and Energy. 2008, 128: 67-73.

[5]. Mehleri ED, Sarimveis H, Markatos NC, et al. A mathematical programming approach for optimal design of distributed energy systems at the neighbourhood level[J]. Energy . 2012, 44(1) : 96-104.

[6]. Siddiqui AS, Marnay C, Edwards JL, et al. Effects of carbon tax on microgrid combined heat and power adoption[J]. Journal of Energy Engineering. 2005, 131(1): 2-25.

[7]. Obara Sy, Watanabe S, Rengarajan B. Operation method study based on the energy balance of an independent microgrid using solar-powered water electrolyzer and an electric heat pump[J]. Energy. 2011, 36(8) : 5200-5213.

[8]. Voorspools KR, D'Haeseleer WD. The evaluation of small cogeneration for residential heating[J]. International Journal of Energy Research. 2002, 26(13): 1175-1190.

[9]. WANG Rui, GU Wei, WU Zhi. Economic and Optimal Operation of a Combined Heat and Power Microgrid with Renewable Energy Resources [J]. Automation of Electric Power Systems. 2011, 35(8): 22-27.

[10]. ZHANG Jie-tan, CHENG Hao-zhong, HU Ze-chun1, et al. Power System Probabilistic Production Simulation Including Wind Farms [J]. Proceedings of the CSEE, 2009, 29(28): 34-39. 
[11]. ZHAO Yu,YU Er-keng. A NEW KIND OF DISTRIBUTED POWER GENERATING EQUIP MENT:MICRO GAS TURBINE [J]. Power System Technology, 2004, (4): 47-50.

[12]. ZHANG Lei, Kang Zi jin, ZHENG Lei, et al. Micro-CHP system [J]. Energy Conservation, 2004 (8): 7-10.

[13]. WEI Bing, WANG Zhi-wei, LI Li, et al. ANALYSIS OF ECONOMIC EFFICIECY FOR COLD,HEAT,AND ELECTRICITY TRIPLE CO-GENENERATION SYSTEM WITH MINIATURE GAS TURBINE [J]. Thermal Power Generation, 2007, 36(9): 1-5.

[14]. WANG Cheng-shan, MA Li, GUO Li. Comparison of Operation Characteristics Between Two Types of Microturbines in Microgrid [J]. Journal of Tianjin University, 2009, 42(4): 316-321.

[15]. Manwell J F, Rogers A, Hayman G, et al. Hybrid2-a hybrid system simulation model, Theory manual. National Renewable Energy Laboratory, Subcontract No[R]. XL-1-11126-1-1, 2006.

[16]. CHEN Jian, WANG Chengshan, ZHAO Bo, et al. Economic Operation Optimization of a Stand-alone Microgrid System Considering Characteristics of Energy Storage System [J]. Automation of Electric Power Systems, 2012, 36(20): 25-31.

[17]. Ministry of Housing and Urban-Rural Construction of the People's Republic of China. JGJ 134-2010 Design stardard for energy efficiency of residential buildings in hot summer and cold winter zone [S]. 2010

[18]. Gang Sun, Ping He. Heating Project [M]. Beijing : China Architecture \& Building Pres, 1993.

[19]. WANG Yang. Reliability Analysis of Microgrid Using Sequential Monte Carlo Simulation Techniques [D]. Chongqing: Chongqing university , 2014. 